\title{
Scanning Photo-Induced Impedance Microscopy using Amorphous Silicon Photodiode Structures
}

\author{
Yinglin Zhou, Li Chen, Steffi Krause*, Jean-Noël Chazalviel ${ }^{1}$ \\ Department of Materials, Queen Mary, University of London, London, E1 4NS, UK \\ ${ }^{1}$ Physique de la Matière Condensée, École Polytechnique, CNRS, 91128 Palaiseau, France \\ s.krause@qmul.ac.uk
}

\section{Supporting information:}

The following shows a Mathcad (version 12) program for calculating the ratio of measured current to local photocurrent according to the equivalent circuit shown in Figure 6 of the publication. The calculation is shown for the example of a $\mathrm{p}-\mathrm{i}-\mathrm{n} / \mathrm{SiO}_{2}$ structure. Figure 1 shows the movement of the laser beam and Figure 2 the equivalent circuit used for the calculation.

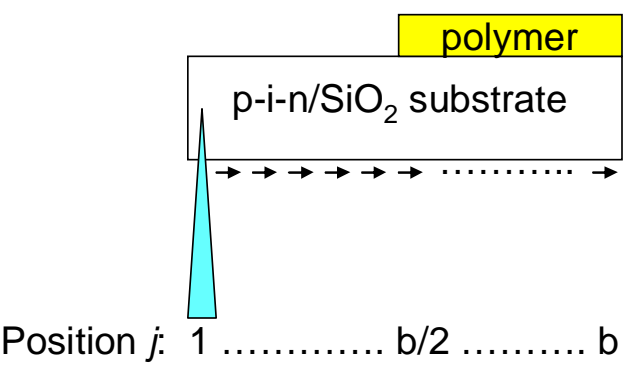

Figure 1 Movement of the laser beam

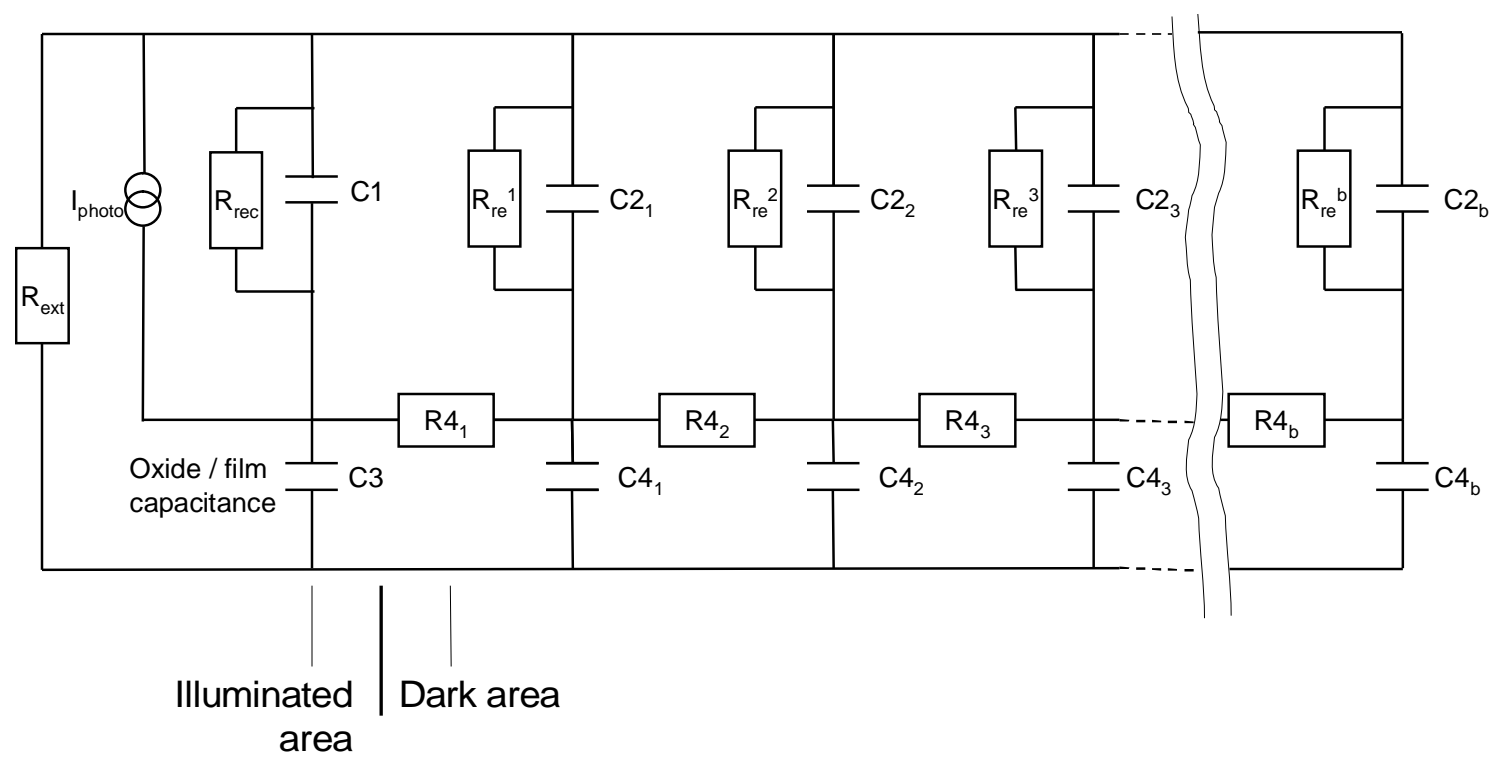

Figure 2 Equivalent circuit used for calculation. The numbered indices of $R_{r e}, R 4, C 2$ and $C 4$ correspond to index $m$ in the calculation. 
All distances are given in $\mathrm{cm}$, resistances in Ohm, capacitances in $\mathrm{F}$. Capacitors and resistors are numbered as in the above circuit.

$\mathrm{b}:=100 \quad$ Number of ladder elements in the equivalent circuit and number of steps for movement of laser spot

$\mathrm{j}:=1 . . \mathrm{b} \quad$ Index for movement of laser spot

$\mathrm{k}:=1 . .5$ Index for frequencies

$\mathrm{m}_{\mathrm{w}}:=1 . . \mathrm{b}$ Index for radius of dark area

Frequencies: $\quad \omega_{\mathrm{k}}:=$

\begin{tabular}{|c|}
\hline $2 \cdot \pi \cdot 10^{5}$ \\
\hline $12 \cdot \pi \cdot 10^{4}$ \\
\hline $2 \cdot \pi \cdot 10^{4}$ \\
\hline $10 \cdot \pi \cdot 10^{3}$ \\
\hline $2 \pi \cdot 10^{3}$ \\
\hline
\end{tabular}

ld $:=10$

Diameter of laser spot in microns

$\mathrm{a}:=10^{-4} \cdot \frac{\mathrm{ld}}{2} \quad$ Radius of illuminated area

$\mathrm{dr}:=10^{-4} \quad$ Radius increments for segments of the dark area

dn $:=35 \cdot 10^{-7} \quad$ Thickness of n-type layer

di $:=50010^{-7} \quad$ Thickness of $\mathrm{i}$ layer

$\kappa n:=2 \times 10^{-3} \quad$ conductivity of n-type a-Si:H

$\kappa i:=10^{-9} \quad$ Recombination conductivity in the dark area

Resistors: $\mathrm{R} 4_{\mathrm{m}}:=\frac{\mathrm{dr}}{\mathrm{a}+\mathrm{dr} \cdot \mathrm{m}} \cdot \frac{1}{2 \pi \cdot \mathrm{dn} \cdot \mathrm{\kappa n}} \quad \begin{aligned} & \text { Estimate of lateral resistance of } \mathrm{n} \text {-type layer for different distances } \\ & \text { from illuminated spot in steps of } \mathrm{dr} .\end{aligned}$

$\operatorname{Rrec}:=\frac{\mathrm{di}}{\pi \cdot 7 \cdot 10^{-5} \cdot \mathrm{a}^{2}}$

Rext $:=100$

$\operatorname{Rre}_{m}:=\frac{d i}{\left[(a+d r \cdot m)^{2}-[a+d r \cdot(m-1)]^{2}\right] \cdot \pi \cdot \kappa i}$ 
Capacitors:

$$
\begin{aligned}
& \mathrm{C} 1:=10^{-5} \cdot \pi \cdot \mathrm{a}^{2}
\end{aligned}
$$

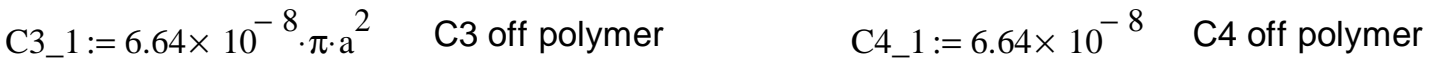

$$
\begin{aligned}
& \text { C3_2:=2× } 10^{-8} \cdot \pi \cdot a^{2} \quad \text { C3 on polymer } \quad \text { C4 } 2:=2 \times 10^{-8} \quad \text { C4 on polymer } \\
& \mathrm{C} 2{ }_{\mathrm{m}}:=1.810^{-8} \cdot\left[(\mathrm{a}+\mathrm{dr} \cdot \mathrm{m})^{2}-[\mathrm{a}+\mathrm{dr} \cdot(\mathrm{m}-1)]^{2}\right] \cdot \pi
\end{aligned}
$$

$\mathrm{C} 3$ and $\mathrm{C4}{ }_{\mathrm{m}}$ change with the position of the laser as the insulator capacitance is greater in the uncoated part of the sample than in the coated part of the sample. This is calculated below.

Calculation of percentage of illuminated area that is on the uncoated part of the sample for any given position $j$ of the laser spot :

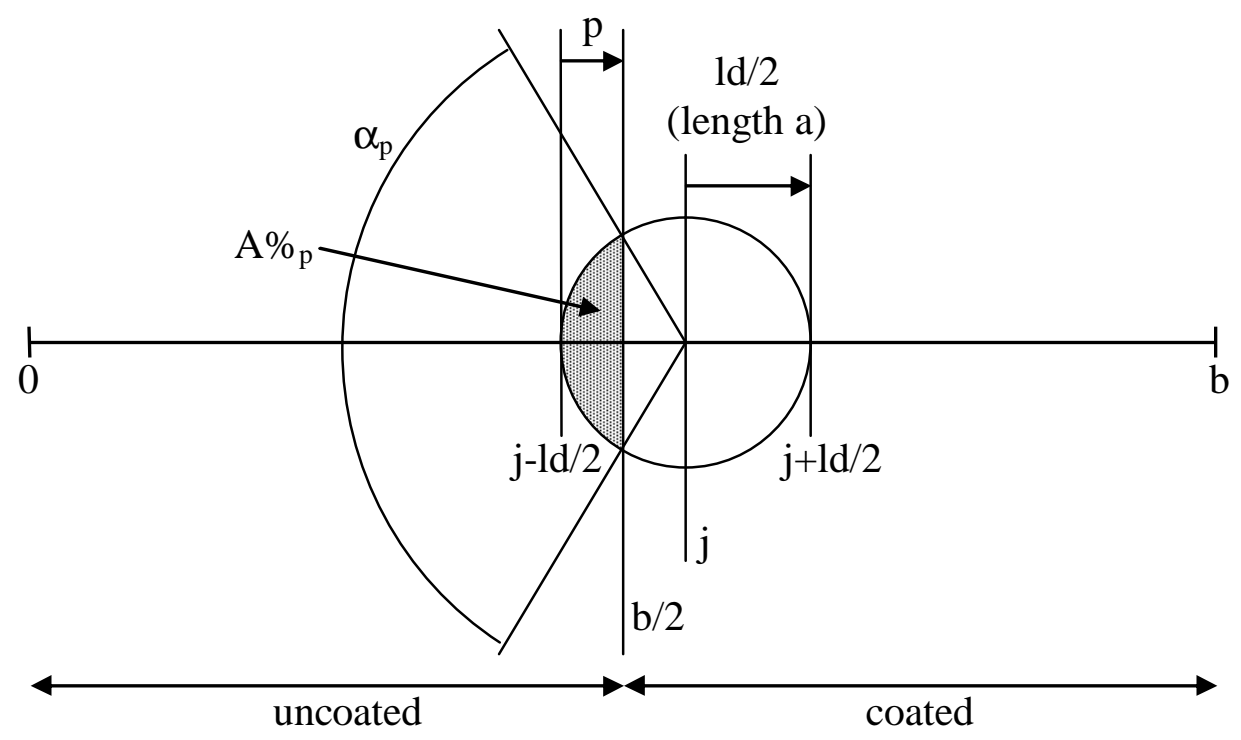

$\mathrm{p}:=0 . . \mathrm{ld} \quad$ width of circle of the illuminated area located in the uncoated area

$$
\begin{aligned}
& \alpha_{p}:=2 \cdot \operatorname{acos}\left(\frac{a-2 p \frac{a}{l d}}{a}\right) \\
& A \%_{p}:=\frac{\frac{\alpha_{p}}{6.283} \cdot a^{2} \cdot \pi-\frac{1}{2} \cdot a^{2} \cdot \sin \left(\alpha_{p}\right)}{\pi \cdot a^{2}}
\end{aligned}
$$


$C 3_{\mathrm{j}}$ is $C 3$ as the illuminated area moves across the polymer edge:

$$
\mathrm{C} 3 \mathrm{j}:=\mid \begin{aligned}
& \mathrm{z} \leftarrow \mathrm{C} 3 \_1 \text { if } \mathrm{j} \leq \frac{\mathrm{b}}{2}-\frac{\mathrm{ld}}{2} \\
& \mathrm{z} \leftarrow \mathrm{C} 3 \_2 \text { if } \mathrm{j} \geq \frac{\mathrm{b}}{2}+\frac{\mathrm{ld}}{2} \\
& \mathrm{z} \leftarrow\left(\begin{array}{c}
1-\mathrm{A} \% \\
\left.\mathrm{j}-\frac{\mathrm{b}}{2}+\frac{\mathrm{ld}}{2}\right)
\end{array}\right)_{\mathrm{z}}^{\cdot \mathrm{C} 3 \_1+\mathrm{A} \% \text { j- } \frac{\mathrm{b}}{2}+\frac{\mathrm{ld}}{2}} \cdot\left(\mathrm{C} 3 \_2\right) \text { if } \frac{\mathrm{b}}{2}-\frac{\mathrm{ld}}{2}<\mathrm{j}<\frac{\mathrm{b}}{2}+\frac{\mathrm{ld}}{2}
\end{aligned}
$$

Calculation of percentage area of each ring segment $m$ of the dark area that has moved across polymer edge at position $j$ of the laser spot:

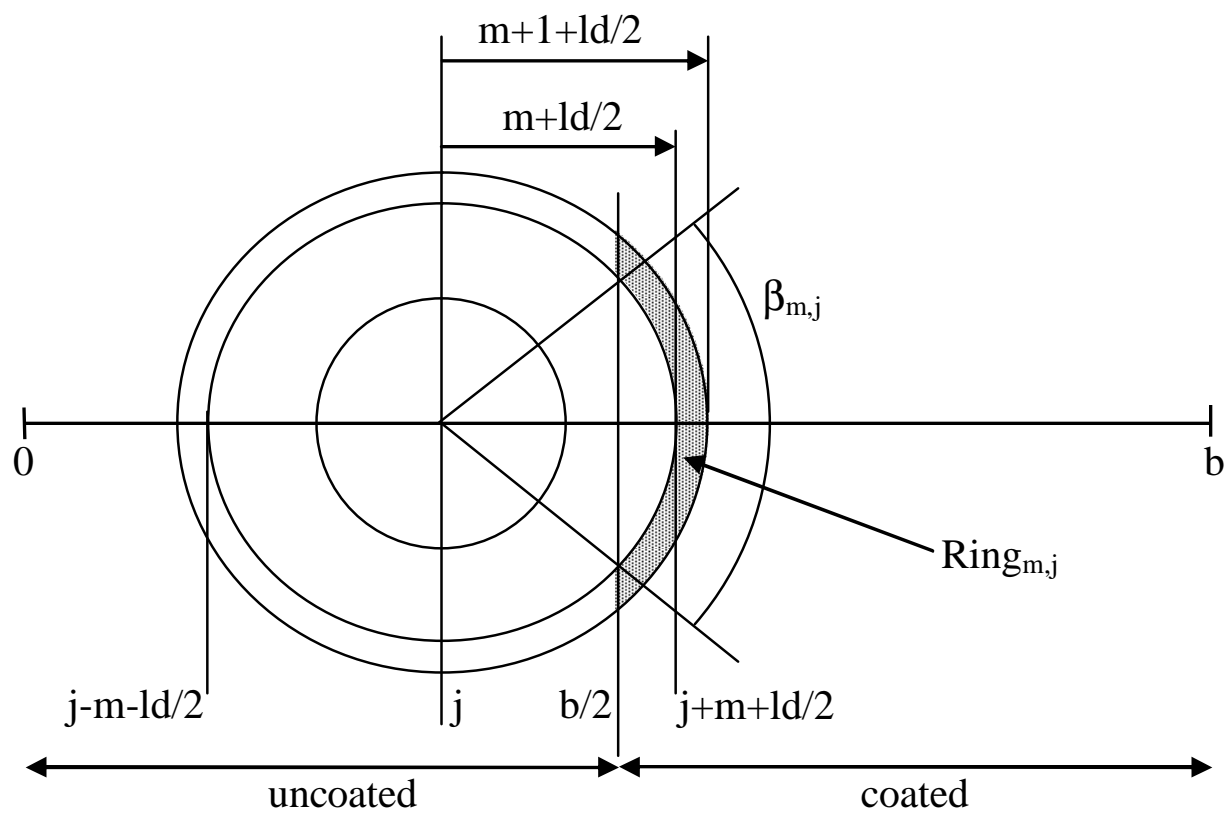

$$
\beta_{\mathrm{m}, \mathrm{j}}:=\mid \begin{array}{ll}
\mathrm{z} \leftarrow 0 & \begin{array}{l}
\beta \text { is the opening angle of the circle } \\
\mathrm{z} \leftarrow 2 \cdot \pi \text { if } \frac{\mathrm{b}}{2}+\mathrm{m}+\frac{\mathrm{ld}}{2} \leq \mathrm{j}
\end{array} \\
\mathrm{z} \leftarrow 0 \text { if } \mathrm{j} \leq \frac{\mathrm{b}}{2}-\mathrm{m}-\frac{\mathrm{ld}}{2} & \begin{array}{l}
\mathrm{m}=\text { index for } \\
\mathrm{j}=\text { index for position }
\end{array} \\
\mathrm{z} \leftarrow 2 \cdot \operatorname{acos}\left[\frac{\frac{\mathrm{ld}}{2}+\mathrm{m}-\left(\mathrm{j}+\frac{\mathrm{ld}}{2}+\mathrm{m}-\frac{\mathrm{b}}{2}\right)}{\frac{\mathrm{ld}}{2}+\mathrm{m}}\right] & \text { if } \frac{\mathrm{b}}{2}-\mathrm{m}-\frac{\mathrm{ld}}{2}<\mathrm{j}<\frac{\mathrm{b}}{2}+\mathrm{m}+\frac{\mathrm{ld}}{2}
\end{array}
$$


$\mathrm{h}:=1 . . \mathrm{b}-1$

$\operatorname{Ring}_{\mathrm{h}, \mathrm{j}}:=\frac{\frac{\beta_{\mathrm{h}+1, \mathrm{j}}}{2 \cdot \pi} \cdot[\mathrm{a}+(\mathrm{h}+1) \mathrm{dr}]^{2} \cdot \pi-\frac{1}{2} \cdot[\mathrm{a}+(\mathrm{h}+1) \cdot \mathrm{dr}]^{2} \cdot \sin \left(\beta_{\mathrm{h}+1, \mathrm{j}}\right)-\left[\frac{\beta_{\mathrm{h}, \mathrm{j}}}{2 \cdot \pi} \cdot[\mathrm{a}+(\mathrm{h}) \mathrm{dr}]^{2} \cdot \pi-\frac{1}{2} \cdot[\mathrm{a}+(\mathrm{h}) \cdot \mathrm{dr}]^{2} \cdot \sin \left(\beta_{\mathrm{h}, \mathrm{j}}\right)\right]}{\pi \cdot[\mathrm{a}+(\mathrm{h}+1) \cdot \mathrm{dr}]^{2}-\pi \cdot[\mathrm{a}+(\mathrm{h}) \cdot \mathrm{dr}]^{2}}$

Capacitance $\mathrm{C} 4$ of oxide/polymer during the scan of the laser spot across the polymer edge for each ring segment of the dark area $h$ and each position of the laser spot $j$ :

$$
\mathrm{C} 4_{\mathrm{h}, \mathrm{j}}:=\mid \begin{aligned}
& \mathrm{z} \leftarrow \mathrm{C} 4 \_2 \cdot\left[\pi \cdot[\mathrm{a}+(\mathrm{h}+1) \cdot \mathrm{dr}]^{2}-\pi \cdot[\mathrm{a}+(\mathrm{h}) \cdot \mathrm{dr}]^{2}\right] \text { if } \frac{\mathrm{b}}{2}+\mathrm{h}+\frac{\mathrm{ld}}{2} \leq \mathrm{j} \\
& \mathrm{z} \leftarrow \mathrm{C} 4 \_1 \cdot\left[\pi \cdot[\mathrm{a}+(\mathrm{h}+1) \cdot \mathrm{dr}]^{2}-\pi \cdot[\mathrm{a}+(\mathrm{h}) \cdot \mathrm{dr}]^{2}\right] \text { if } \mathrm{j} \leq \frac{\mathrm{b}}{2}-\mathrm{h}-\frac{\mathrm{ld}}{2} \\
& \mathrm{z} \leftarrow \pi \cdot\left[[\mathrm{a}+(\mathrm{h}+1) \cdot \mathrm{dr}]^{2}-[\mathrm{a}+(\mathrm{h}) \cdot \mathrm{dr}]^{2}\right] \cdot\left[\mathrm{C} 4 \_1 \cdot\left(1-\operatorname{Ring}_{\mathrm{h}, \mathrm{j}}\right)+\mathrm{C} 4 \_2 \cdot \operatorname{Ring} \mathrm{h}, \mathrm{j}\right] \text { if } \frac{\mathrm{b}}{2}-\mathrm{h}-\frac{\mathrm{ld}}{2}<\mathrm{j}<\frac{\mathrm{b}}{2}+\mathrm{h}+\frac{\mathrm{ld}}{2} \\
& \mathrm{z}
\end{aligned}
$$

The ladder circuit can be redrawn as the following three-terminal circuit (the values of a, b, c may differ at each step):

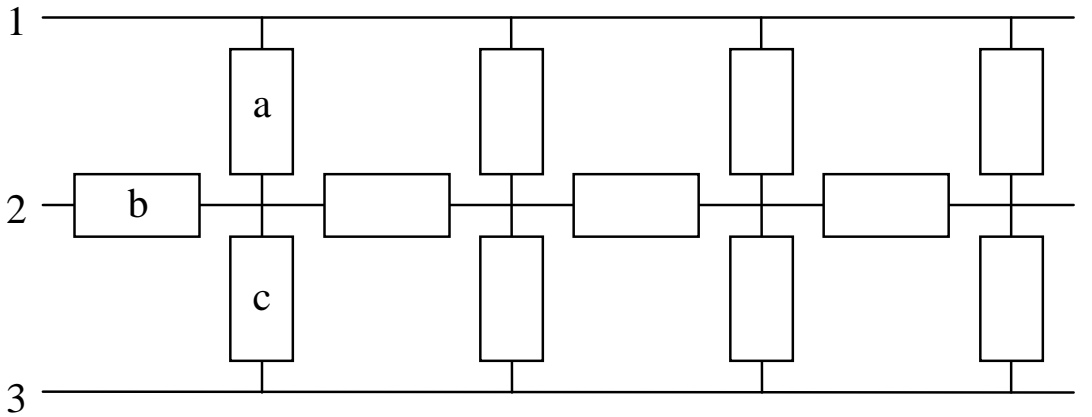

This three-terminal circuit is equivalent to a three-impedance box:

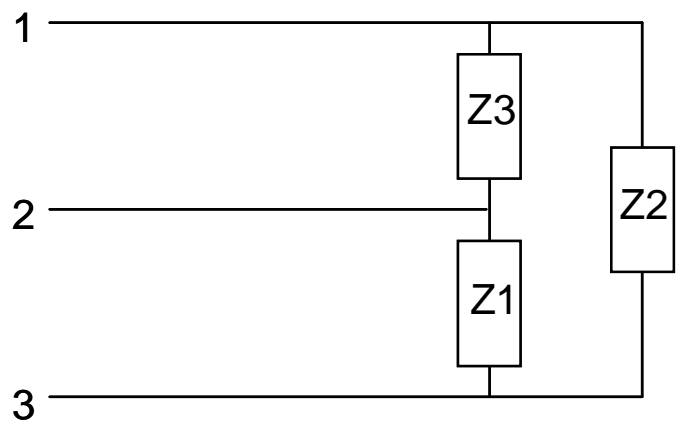

$\mathrm{Z1}, \mathrm{Z} 2$ and $\mathrm{Z} 3$ for the ladder circuit can be calculated by iteration. Let us assume that this task has been performed to level $n-1$, i.e., the (n-1)-cell circuit is equivalent to $z 1, z 2$, $z 3$ (lower case letters are used instead of the $n-1$ subscripts). Then to order $n$, we can calculate Z1, Z2, Z3 (upper case letters are used instead of the $\mathrm{n}$ subscripts): 


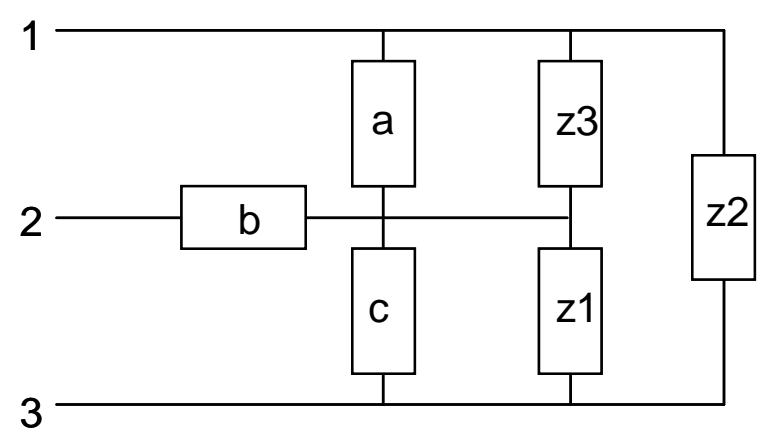

If terminals 1 and 2 are short-circuited, we measure the impedance between (1-2) and 3, which gives

$$
\frac{1}{\mathrm{Z} 1}+\frac{1}{\mathrm{Z} 2}=\frac{1}{\mathrm{z} 2}+\frac{1}{\frac{1}{\mathrm{c}+\frac{1}{\mathrm{z} 1}}+\frac{1}{\frac{1}{\mathrm{~b}}+\frac{1}{\mathrm{z} 3}+\frac{1}{\mathrm{a}}}}
$$

In the same way, by short-circuiting 2 and 3 and measuring between 1 and (2-3), we get

$$
\frac{1}{\mathrm{Z} 2}+\frac{1}{\mathrm{Z} 3}=\frac{1}{\mathrm{z} 2}+\frac{1}{\frac{1}{\frac{1}{\mathrm{a}}+\frac{1}{\mathrm{z} 3}}+\frac{1}{\frac{1}{\mathrm{~b}}+\frac{1}{\mathrm{c}}+\frac{1}{\mathrm{z} 1}}}
$$

and by short-circuiting 1 and 3 and measuring between 2 and (1-3), we get

$$
\frac{1}{\mathrm{Z} 1}+\frac{1}{\mathrm{Z} 3}=\frac{1}{\mathrm{~b}+\frac{1}{\frac{1}{\mathrm{a}}+\frac{1}{\mathrm{z} 3}+\frac{1}{\mathrm{c}}+\frac{1}{\mathrm{z} 1}}}
$$

From these three equations $Z 1, Z 2, Z 3$ can be calculated as a function of a,b,c, and z1,z2,z3.

The complete circuit without load can be represented by

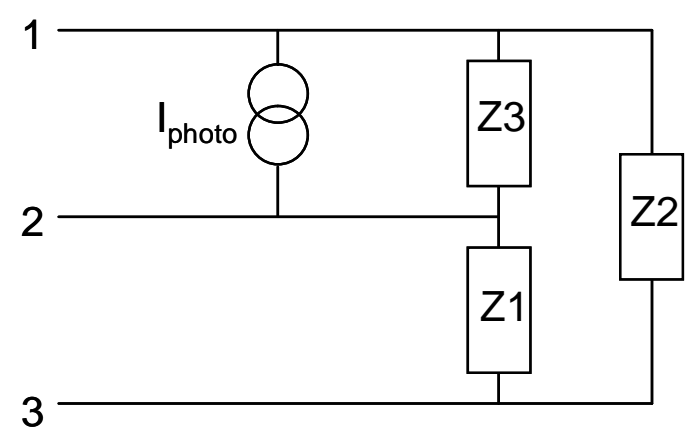


If the circuit is loaded by an external resistor $R_{\text {ext }}$ located between 1 and 3 , the circuit can be redrawn:

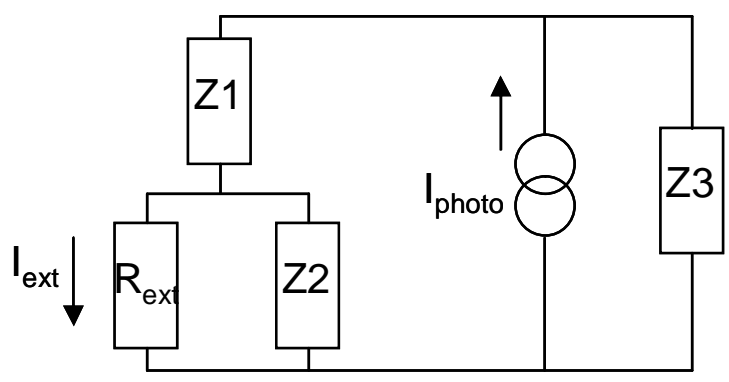

allowing for a straightforward calculation of the ratio $I_{\text {ext }} / l_{\text {photo }}$.

In practice, the calculations were performed as follows:

The ladder circuit:

$$
\begin{aligned}
& \mathrm{Za}_{\mathrm{k}}:=\frac{1}{\mathrm{i} \cdot \omega_{\mathrm{k}} \cdot \mathrm{C} 2_{\mathrm{b}-1}+\frac{1}{\mathrm{Rre}_{\mathrm{b}-1}}} \\
& \mathrm{Zb}:=\mathrm{R} 4_{\mathrm{b}-1} \\
& \mathrm{Zc}_{\mathrm{j}, \mathrm{k}}:=\frac{1}{\mathrm{i} \cdot \omega_{\mathrm{k}} \cdot \mathrm{C} 4_{\mathrm{b}-1, \mathrm{j}}}
\end{aligned}
$$




$$
\mathrm{Z1}_{\mathrm{j}, \mathrm{k}}:=\frac{\mathrm{Zc}_{\mathrm{j}, \mathrm{k}} \cdot \mathrm{Zb}+\mathrm{Zc}_{\mathrm{j}, \mathrm{k}} \cdot \mathrm{Za}_{\mathrm{k}}+\mathrm{Za}_{\mathrm{k}} \cdot \mathrm{Zb}}{\mathrm{Za}_{\mathrm{k}}} \quad \mathrm{Z}_{\mathrm{j}, \mathrm{k}}:=\frac{\mathrm{Zc}_{\mathrm{j}, \mathrm{k}} \cdot \mathrm{Zb}+\mathrm{Zc}_{\mathrm{j}, \mathrm{k}} \cdot \mathrm{Za}_{\mathrm{k}}+\mathrm{Za}_{\mathrm{k}} \cdot \mathrm{Zb}}{\mathrm{Zb}} \quad \mathrm{Z}_{\mathrm{j}, \mathrm{k}}:=\frac{\mathrm{Zc_{j } , \mathrm { k }} \cdot \mathrm{Zb}+\mathrm{Zc}_{\mathrm{j}, \mathrm{k}} \cdot \mathrm{Za}_{\mathrm{k}}+\mathrm{Za}_{\mathrm{k}} \cdot \mathrm{Zb}}{\mathrm{Zc}_{\mathrm{j}, \mathrm{k}}}
$$

$\operatorname{Current}(\mathrm{j}, \mathrm{k}):=\left[\mid \begin{array}{l}\mathrm{z} 1 \leftarrow \mathrm{Z}_{\mathrm{j}, \mathrm{k}} \\ \mathrm{z} 2 \leftarrow \mathrm{Z} 2_{\mathrm{j}, \mathrm{k}} \\ \mathrm{z} 3 \leftarrow \mathrm{Z} 3_{\mathrm{j}, \mathrm{k}}\end{array}\right.$

for $\mathrm{n} \in \mathrm{b}-2 . .1$

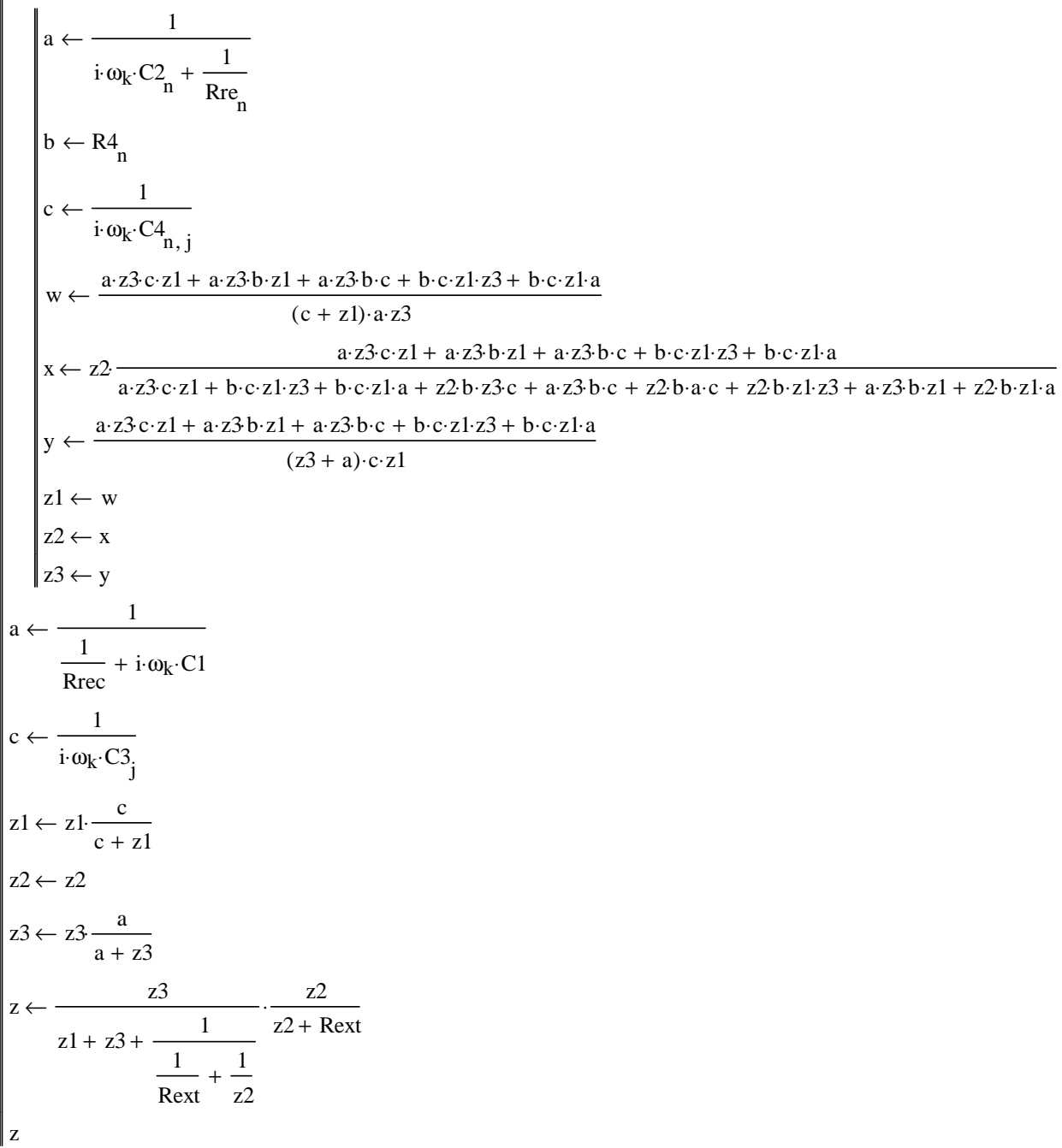

$I_{j, k}:=\operatorname{Current}(j, k)$ 


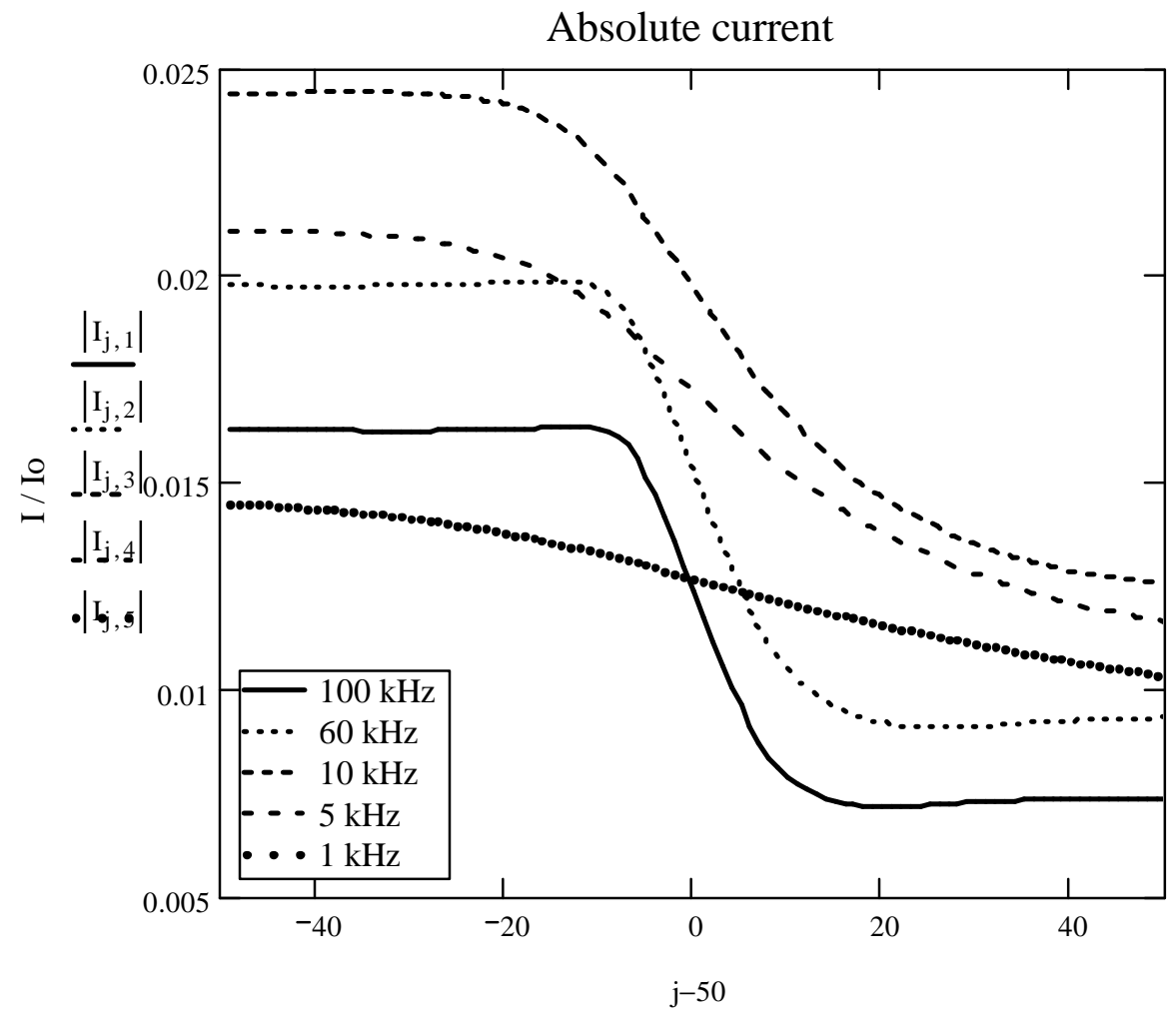

$\mathrm{X} /$ microns

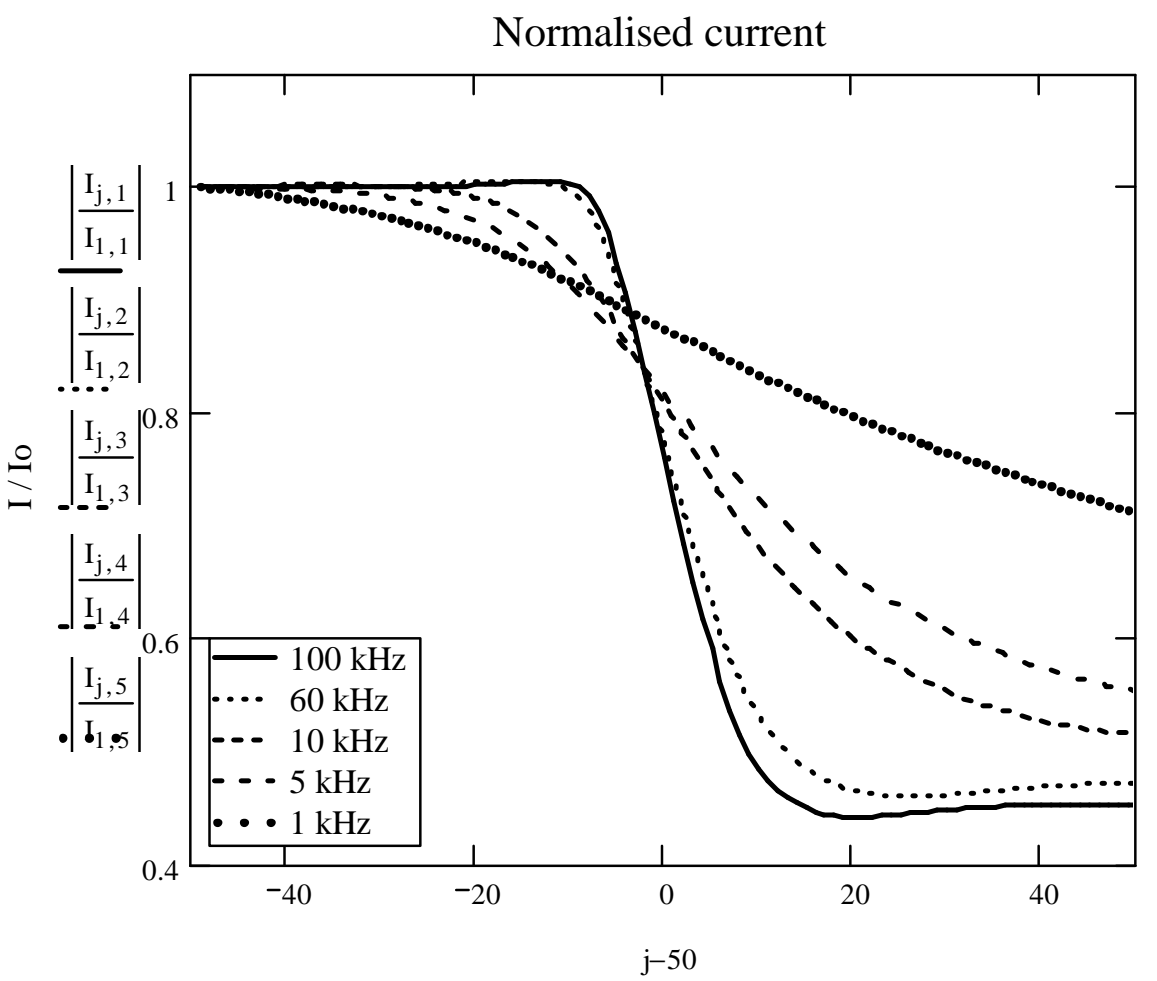

$\mathrm{X} /$ microns 